\title{
MALIGNANT MELANOMA OF THE LIMBUS INVOLVING THE WHOLE CORNEA* REPORT OF A CASE
}

\author{
BY \\ P. SIVA REDDY AND O. M. SATYENDRAN \\ Institute of Ophthalmology and Sarojini Devi Eye Hospital, Hyderabad, India
}

MALIGNANT melanoma of the cornea is rare as a primary or secondary lesion, less than twenty cases having been reported (Schofield, 1958).

\section{Case Report}

A woman aged about 40 (Fig. 1) stated that a growth had begun in the limbal area 3 months previously and had gradually increased in size to involve the anterior part of the eye.

Examination.-The tumour protruded forwards in the palpebral aperture; it was irregular in shape, dark coloured, and firm in consistency, and bled easily at a touch.

Operation.-The tumour was excised (Fig. 2) and was seen to be dark brown in colour, involving the whole of the anterior surface of the cornea and extending all around the limbal region. In sagittal paramedian section it measured $2.75 \mathrm{~cm}$. vertically, and was $8 \mathrm{~mm}$. thick. No intraocular involvement was noted.

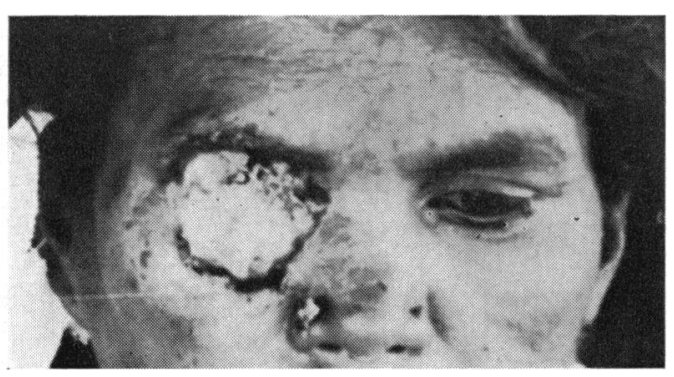

Fig. 1.-Melanoma of cornea and limbus.

Fig. 2.-Excised neoplasm with anterior segment of the globe.

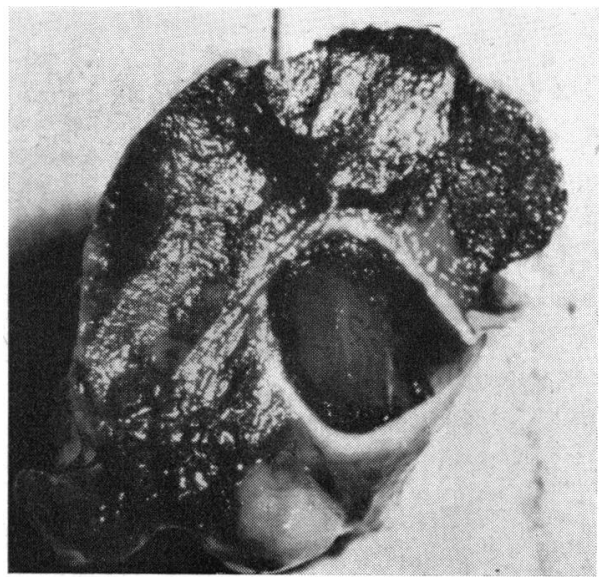

Histological Study.-The sections examined were variably pigmented. The anterior layers of the cornea were involved with destruction of the epithelium and of Bowman's membrane (Fig. 3, opposite).

The cells, which were predominantly epithelioid in type with vesicular nuclei and a fair amount of cytoplasm, were arranged in alveolar and naevus patterns with thin intervening fibrous strands. Squamous characteristics were absent. Pleomorphism and anaplasia were noted in the deeper parts of the section (Fig. 4, opposite).

Follow-up.-The patient was last seen 2 years and 1 month post-operatively. At this time there was no recurrence of the growth in the eye and the operative site had healed. A general physical examination revealed no neoplasm or secondaries throughout the body.

* Received for publication November 25, 1963. 


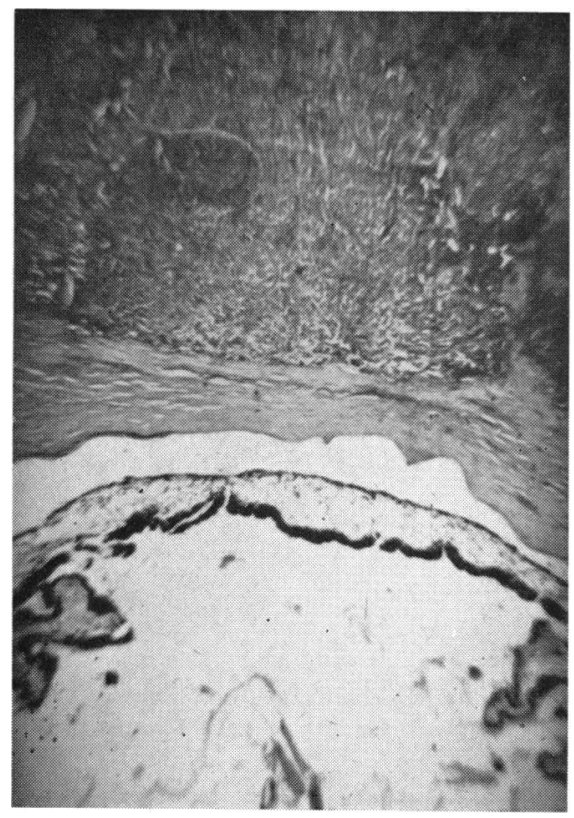

FIG. 3.-Section, showing involvement of anterior layers of the cornea.

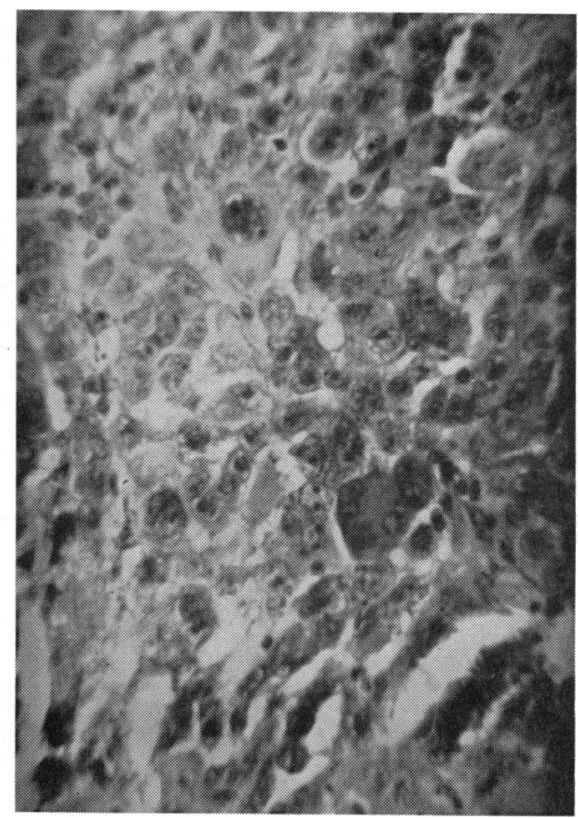

FIG. 4.-Histological section, showing cellular pleomorphism. $\times 500$.

\section{Comment}

Malignant melanomata of the eye and its adnexa are rarely seen in this hospital practice, which treats 30,000 to 40,000 new cases in the ophthalmic out-patients department and over 5,000 in-patients annually. From January, 1959, to July, 1961, only three cases of malignant melanoma were recorded in the pathology register.

The accepted treatment of bulbar malignant melanoma is by excision of the eyeball. Exenteration of the orbit is advised by Reese (1951), but Ash (1950) found that simple excision was effective in fourteen out of eighteen cases of epibulbar malignant melanoma.

In our case the history clearly indicated that the neoplasm had its origin at the limbus, and histological study confirmed the continuity of the growth over the cornea and the limbal area.

The prognosis in epibulbar malignant melanoma is not good. Ash (1950) reported that, of 49 cases followed for a period of 5 years or more, fourteen had died; four of these cases had recurrences or metastases at the time of death, and 14 per cent. of the living patients also had recurrences and/or metastases.

\section{REFERENCES}

AsH, J. E. (1950). Amer. J. Ophthal., 33, 1203.

REESE, A. B. (1951). "Tumors of the Eye", p. 330. Hoeber, New York.

SChofield, P. B. (1958). Brit. J. Ophthal., 42, 99. 